\title{
ASSOCIATION BETWEEN HISTOCOMPATABILITY ANTIGENS (HLA) AND NASAL CARRIAGE OF STAPHYLOCOCCUS AUREUS
}

\author{
Oonagh S. Kinsman, Rachel McKenna* and W. C. Noble \\ Department of Bacteriology, Institute of Dermatology, \\ Homerton Grove, London E9, and \\ * Department of Medicine, Regional Hospital, Galway, Ireland
}

\begin{abstract}
SUMmaRY. We investigated the association between phenotypes of histocompatability antigen (HLA) and nasal carriage of Staphylococcus aureus in two populations - healthy laboratory workers and patients attending an outpatients' clinic. When data from the two sources were pooled, it was evident that the presence of HLA-DR3 was associated with carriage, and the presence of HLA-DR2, HLA-DR1 and HLA-Bw35 with lack of carriage. However, since each person may have two antigenic specificities encoded at the HLA-A, the HLA-B, and the HLA-DR loci, the carriage of the organism was analysed for paired combinations of the more frequent phenotypes. For example, the lack of carriage evident with HLA-DR1 was more marked with the DR1-A11 and DR1-B7 combinations while the predisposition towards carriage shown with HLA-DR3 was more marked with the DR3-DR5 combination. The importance of the analysis of antigen combinations is discussed in relation to association of single antigens with carriage of $S$. aureus.
\end{abstract}

\section{INTRODUCTION}

There appear to be three main classes of nasal carrier of Staphylococcus aureus: the persistent carrier, the persistent non-carrier and the intermittent carrier (Williams, 1963) but no convincing reason for this has yet been put forward. A genetic predisposition to nasal carriage among healthy subjects has been recognized for some time. Noble, Valkenburg and Wolters (1967) analysed carriage within families and found that predisposition to the carrier state was not explained simply by exposure to a common reservoir of bacteria. In addition, from studies on twins, Hoeskma and Winkler (1963) showed that the percentage similarity in carriage was greater in identical twins than non-identical twins or unrelated children. Finally it has been observed that there are some racial differences, e.g., negroids carry $S$. aureus less frequently than do caucasoids (Findlay and Abrahams, 1946; Millian et al., 1960; Noble, 1974).

We investigated the possible association between HLA type and nasal carriage of $S$. aureus in an attempt to explain this genetic predisposition and to study further the colonization of mucosa by this organism.

\section{MATERIALS AND METHODS}

Subjects. Nasal carriage of $S$. aureus was investigated in two populations. The first, of 90 adults, was studied in Ireland and consisted of people who had donated blood for HLA typing other studies and was mostly made up of patients attending outpatient clinics in Dublin and Galway. The diagnoses were as follows: Graves's disease 62, coeliac disease 14, psoriasis 8, and juvenile-onset diabetes 6 . Antigens of the HLA-A and -B series were detected by the standard NIH Terasaki microlymphocytotoxicity test, and of the HLA-DR series by a cytotoxicity test after B-cell enrichment according to van Rood et al. (1975) with a total of 60 B-cell antisera. The second population was of 90 healthy laboratory workers in London on whom HLA typing 
had been performed, by standard techniques and for reasons other than the present study, in one of four tissue-typing centres.

Bacteriology. Swabs were taken from the anterior nares and placed in Amies's Transport Medium. In the laboratory they were seeded on to nutrient agar and mannitol-salt agar (Oxoid). All coagulase-positive staphylococci isolated were maintained on nutrient-agar slopes and subsequently phage typed. Each person was swabbed only once and those yielding more than three colonies of $S$. aureus were designated carriers.

Analysis of results. Antigens Aw23 and Aw24 were grouped with antigen A9, from which they have only recently been separated; similarly, Bw51 was grouped with B5 and Bw44 with B12.

Relations between carriage of $S$. aureus and HLA phenotype were sought by determining the relative risk of carriage associated with the possession of each antigen or antigen combination. This was defined as

$$
\frac{a}{b} \times \frac{d}{c}
$$

where $a=$ the number of persons with the antigen or antigens who were carriers, $b=$ the number with the antigen or antigens who were non-carriers, $c=$ the number without the antigen or antigens who were carriers, and $d=$ the number without the antigen or antigens who were non-carriers. Significant departures from a relative risk value of 1.0 were determined by means of Fisher's exact test, but probabilities were not adjusted for the number of antigens for which tests had been made (the Bodmer correction factor) because this would have been meaningless when analysing results in respect of combinations of antigens.

\section{RESULTS}

The frequency of nasal carriage in the sample of laboratory workers was $30 \%$. This corresponds well with results from previous studies (Williams, 1963). The patient group had a slightly higher frequency $(41 \%)$ than the laboratory workers but the difference was not significant $\left(\chi^{2}\right.$ test: $\left.p>0.05\right)$. Length of stay in hospital may increase the frequency of nasal carriage of $S$. aureus (Ayliffe et al., 1977), but none of our patients was in hospital when included in the sample.

Table I shows the frequencies of the more common HLA phenotypes of the two populations studied, together with the associated relative risk of carriage of $S$. aureus. The distribution of individual antigens in the two groups was markedly different, but the patients included a number with diagnoses expected to be associated with the presence of antigens B8 and DR3.

For antigens in the HLA-A and HLA-B series, the only statistically significant associations were those between lack of carriage and the presence of antigen $\mathrm{A} 3$ or Bw35 in the laboratory-workers' group; in the patients' group there was a non-significant trend in the same direction (relative risk $<1 \cdot 0$ ). For antigens in the HLA-DR series, there was agreement in trend in respect of five of the seven antigens, towards non-carriage in bearers of antigens DR1, DR2 and DR4, and towards carriage (relative risk $>1.0$ ) in bearers of antigens DR3 and DR7. These reached statistical significance for DR 1 in both groups, and for DR 1, DR2 and DR 3 only in the patients' group. With two of the antigens-DR5 and DRw6-the trends were contradictory; the presence of DRw6 showed a significant association with non-carriage in the laboratory workers and with carriage in the patients. However, further inspection suggested that these anomalies might be explained by the contribution of other antigens expressed by the same subjects, because each of them may have two antigenic specificities at HLA-A, HLA-B or HLA-DR loci. For example, in the case of HLA-DR5, 12 of the 22 patients expressing DR5 also expressed DR3 but none of the 15 laboratory workers with DR5 expressed DR3.

Thus it may be more relevant to consider antigen combinations than individual antigens. For this purpose we thought it permissible to increase the number of combinations available for comparison by bringing together the results obtained in the two series. It seemed reasonable to assume that, though the two groups differed in HLA constitution, they would show a similar relation of HLA phenotype to nasal carriage. Selected results are shown in table II. The relative 
TABLE I

Frequency of occurrence of individual HLA phenotypes, and of carriage of $S$. aureus associated with them, in laboratory workers and patients

\begin{tabular}{|c|c|c|c|c|c|c|}
\hline \multirow[b]{2}{*}{ HLA antigen } & \multicolumn{3}{|c|}{ Laboratory workers } & \multicolumn{3}{|c|}{ Patients } \\
\hline & $\begin{array}{l}\text { Frequency } \\
\text { of the stated } \\
\text { antigen }\end{array}$ & $\begin{array}{c}\text { Relative } \\
\text { risk } \\
\text { of carriage } †\end{array}$ & $\mathrm{p}=$ & $\begin{array}{l}\text { Frequency } \\
\text { of the stated } \\
\text { antigen* }\end{array}$ & $\begin{array}{c}\text { Relative } \\
\text { risk } \\
\text { of carriage } \dagger\end{array}$ & $\mathrm{p}=$ \\
\hline $\begin{array}{l}\text { HLA-A1 } \\
\text { HLA-A2 } \\
\text { HLA-A3 } \\
\text { HLA-A9/w23/w24 } \\
\text { HLA-A11 } \\
\text { HLA-A26 } \\
\text { HLA-A29 }\end{array}$ & $\begin{array}{r}27 \\
43 \\
17 \\
20 \\
14 \\
9 \\
6\end{array}$ & $\begin{array}{l}1.72 \\
1.56 \\
0.25 \\
0.47 \\
0.59 \\
1 \cdot 18\end{array}$ & $\begin{array}{l}0 \cdot 106 \\
0 \cdot 115 \\
0 \cdot 045 \\
0 \cdot 109 \\
0 \cdot 199 \\
0 \cdot 281\end{array}$ & $\begin{array}{r}41 \\
51 \\
21 \\
14 \\
8 \\
0 \\
8\end{array}$ & $\begin{array}{l}1.48 \\
1.08 \\
0.84 \\
1.08 \\
0.44 \\
0.84\end{array}$ & $\begin{array}{l}0 \cdot 110 \\
0 \cdot 119 \\
0 \cdot 191 \\
0 \cdot 227 \\
0 \cdot 197 \\
0.287\end{array}$ \\
\hline $\begin{array}{l}\text { HLA-B5/w51 } \\
\text { HLA-B7 } \\
\text { HLA-B8 } \\
\text { HLA-B12/w44 }\end{array}$ & $\begin{array}{r}8 \\
16 \\
15 \\
23\end{array}$ & $\begin{array}{l}2.56 \\
1.07 \\
0.77\end{array}$ & $\begin{array}{c}0.134 \\
0.230 \\
\ddot{0} \cdot 190\end{array}$ & $\begin{array}{r}9 \\
20 \\
45 \\
28\end{array}$ & $\begin{array}{l}0.69 \\
0.39 \\
1.71 \\
0.89\end{array}$ & $\begin{array}{l}0.252 \\
0.053 \\
0.079 \\
0.178\end{array}$ \\
\hline $\begin{array}{l}\text { HLA-B13 } \\
\text { HLA-B14 }\end{array}$ & $\begin{array}{l}6 \\
6\end{array}$ & $\cdots$ & $\ldots$ & $\begin{array}{l}4 \\
8\end{array}$ & $2 \cdot 60$ & $0 \cdot 131$ \\
\hline HLA-B 15 & 8 & 0.76 & 0.307 & 4 & $\cdots$ & $\cdots$ \\
\hline HLA-B18 & 9 & 2.01 & $0 \cdot 174$ & 1 & 1.85 & 0.160 \\
\hline HLA-Bw35 & $\begin{array}{l}11 \\
13\end{array}$ & $\begin{array}{l}0.85 \\
0.16\end{array}$ & 0.043 & $\begin{array}{l}11 \\
14\end{array}$ & $\begin{array}{l}1.85 \\
0.33\end{array}$ & $\begin{array}{l}0.160 \\
0.065\end{array}$ \\
\hline HLA-B40 & 6 & $\ldots$ & $\ldots$ & 6 & $\cdots$ & $\cdots$ \\
\hline $\begin{array}{l}\text { HLA-DR1 } \\
\text { HLA-DR2 } \\
\text { HLA-DR3 } \\
\text { HLA-DR4 } \\
\text { HLA-DR5 } \\
\text { HLA-DRw6 } \\
\text { HLA-DR7 }\end{array}$ & $\begin{array}{l}20 \\
28 \\
16 \\
32 \\
15 \\
15 \\
27\end{array}$ & $\begin{array}{l}0.51 \\
0.90 \\
1 \cdot 02 \\
0.86 \\
0.82 \\
0.13 \\
2 \cdot 01\end{array}$ & $\begin{array}{l}0 \cdot 120 \\
0 \cdot 193 \\
0 \cdot 240 \\
0 \cdot 183 \\
0 \cdot 230 \\
0.022 \\
0.069\end{array}$ & $\begin{array}{r}21 \\
28 \\
49 \\
24 \\
22 \\
9 \\
17\end{array}$ & $\begin{array}{l}0.36 \\
0.35 \\
2.51 \\
0.63 \\
2.06 \\
5.95 \\
1.00\end{array}$ & $\begin{array}{l}0.038 \\
0.021 \\
0 \cdot 019 \\
0.130 \\
0.067 \\
0.020 \\
0.210\end{array}$ \\
\hline
\end{tabular}

Figures in bold type indicate a statistically significant association with carriage or non-carriage.

* Number (of 90 subjects) with the stated antigen.

+ See Materials and Methods.

risk of carriage is given for each antigen individually, and for antigen combinations when their frequency was greater than five. Although each person may express six antigenic specificities, only paired combinations are shown. In the combined populations, three antigens (Bw35, DR2 and DR1) were significantly associated with lack of carriage while one antigen (DR3) was associated with carriage. However, when the results for combinations of antigens were assessed it was evident that the relative risk was much reduced for certain antigen combinations; for example, the overall relative risk for DR 1 was 0.4 whereas that of the combinations DR 1 -All and DR1-B7 was reduced to zero. The figures in bold type denote a significant association with carriage or lack of carriage. Thus some antigen combinations predispose towards lack of carriage of $S$. aureus while others predispose towards carriage or are indeterminate in effect. It is notable that predisposition towards lack of carriage associated with antigen DR 1 or Bw35 seems to be dominant when in combination with other phenotypes, but further data is necessary to clarify this point.

There was no evidence of an association between the phage type of the $S$. aureus strains isolated and the HLA type of the carrier.

\section{Discussion}

We have shown that certain HLA phenotypes apparently predispose towards nasal carriage of $S$. aureus and others predispose towards lack of carriage. This is most marked with particular combinations of antigens. The potential importance of combinations of antigens has been 
TABLE II

Association between relative risk of carriage of $S$. aureus and some HLA phenotype-combinations in a conflated group of 180 laboratory workers and patients

\begin{tabular}{|c|c|c|c|c|c|c|c|c|}
\hline \multirow[b]{2}{*}{ HLA phenotype } & \multirow{2}{*}{$\begin{array}{l}\text { Relative risk of carriage* } \\
\text { for single HLA }\end{array}$} & \multicolumn{7}{|c|}{$\begin{array}{l}\text { Relative risk of carriage* for combination of the } \\
\text { stated phenotype with phenotype }\end{array}$} \\
\hline & & $\mathrm{A} 3$ & All & B8 & Bw35 & DR3 & DR2 & DR1 \\
\hline $\begin{array}{l}\text { A1 } \\
\text { A2 } \\
\text { A9/w23/w24 } \\
\text { A3 } \\
\text { A11 }\end{array}$ & $\begin{array}{l}1.4(68) \\
0.9(94) \\
0.6(38) \\
0.6(38) \\
0.4(22)\end{array}$ & $\begin{array}{c}0.5(8) \\
1 \cdot 4(11) \\
\ldots\end{array}$ & $\begin{array}{c}0 \cdot 2(7) \\
\ldots \\
\ldots \\
\ldots\end{array}$ & $\begin{array}{l}1 \cdot 3(43) \\
1 \cdot 2(22) \\
0 \cdot 9(11) \\
0 \cdot 6(7)\end{array}$ & $\begin{array}{c}\dddot{0}(10) \\
0.5(8) \\
0.6(7) \\
0(6)\end{array}$ & $\begin{array}{l}1.6(42) \\
0.9(33) \\
1.5(13) \\
1.7(6)\end{array}$ & $\begin{array}{l}0 \cdot 7(10) \\
0 \cdot 6(25) \\
0 \cdot 6(7) \\
0 \cdot 5(20) \\
0 \cdot 1(11)\end{array}$ & $\begin{array}{l}0.3(12) \\
0.4(17) \\
0.4(9) \\
0.5(8) \\
0(7)\end{array}$ \\
\hline $\begin{array}{l}\text { B27 } \\
\text { B8 } \\
\text { B12/w44 } \\
\text { B7 } \\
\text { Bw35 }\end{array}$ & $\begin{array}{l}1.2(22) \\
1.0(60) \\
0.8(51) \\
0.5(36) \\
0.3(27)\end{array}$ & $\begin{array}{l}0 \cdot 6(7) \\
1 \cdot 3(9) \\
0 \cdot 3(18) \\
0 \cdot 6(7)\end{array}$ & $\begin{array}{c}0 \cdot 8(7) \\
\ldots \\
\ldots \\
0(6) \\
0(6)\end{array}$ & $\begin{array}{c}1 \cdot 7(12) \\
\ldots \\
\ldots\end{array}$ & $\begin{array}{c}0 \cdot 8(6) \\
\ldots\end{array}$ & $\begin{array}{l}4 \cdot 5(7) \\
1.8(44) \\
1 \cdot 3(16) \\
0.5(8)\end{array}$ & $\begin{array}{l}0 \cdot 2(7) \\
0 \cdot 4(10) \\
0 \cdot 6(17) \\
0.4(17) \\
0.6(7)\end{array}$ & $\begin{array}{c}0.3(11) \\
0.7(10) \\
0(7) \\
0.4(10)\end{array}$ \\
\hline $\begin{array}{l}\text { DR3 } \\
\text { DR7 } \\
\text { DR5 } \\
\text { DRw6 } \\
\text { DR4 } \\
\text { DR2 } \\
\text { DR1 }\end{array}$ & $\begin{array}{l}1.9(65) \\
1.4(44) \\
1.3(37) \\
0.8(24) \\
0.6(54) \\
0.5(56) \\
0.4(41)\end{array}$ & $\begin{array}{c}3 \cdot 5(6) \\
\ldots \\
\ldots \\
\mathbf{0}(8) \\
0.5(20) \\
0.5(8)\end{array}$ & $\begin{array}{c}1 \cdot 7(6) \\
0.8(6) \\
\ldots\end{array}$ & $\begin{array}{l}1 \cdot 8(44) \\
1 \cdot 3(9) \\
2 \cdot 3(7) \\
1 \cdot 2(7) \\
0 \cdot 4(13) \\
0 \cdot 4(10) \\
0 \cdot 3(11)\end{array}$ & $\begin{array}{l}\ldots \\
\cdots \\
\cdots \\
\cdots \\
0 \cdot 6(7) \\
0 \cdot 4(10)\end{array}$ & $\begin{array}{l}3 \cdot 5(6) \\
\mathbf{3} \cdot \mathbf{6}(9) \\
2 \cdot 3(7) \\
1 \cdot 0(16) \\
1 \cdot 1(10) \\
0 \cdot 3(11)\end{array}$ & $\begin{array}{l}1 \cdot 1(10) \\
1.4(11) \\
0 \cdot 5(8) \\
0.4(10) \\
0 \cdot 4(9)\end{array}$ & $\begin{array}{c}0 \cdot 3(11) \\
\ldots \\
\ldots \\
\ldots\end{array}$ \\
\hline
\end{tabular}

In parentheses: frequency (among 180 subjects) of HLA phenotype or phenotype-combination; $\ldots=$ frequency $<6$; in bold type: $\mathrm{p}<0.05$.

* See Materials and Methods.

emphasized recently (Kaslow and Shaw, 1981). Linkage disequilibrium refers to the situation in which certain combinations occur more frequently than would be expected if the alleles were randomly distributed, e.g., A1-B8-DR3, and suggests some selective advantage. From the present study it is also obvious that in the populations studied certain combinations occur more frequently than others. A gene or genes responsible for carriage or lack of carriage of $S$. aureus may be closely linked with the HLA locus or, rather, it may be in linkage disequilibrium with certain HLA phenotypes. Linkage may be determined by investigating carriage in relation to HLA haplotypes but these can be determined only from family studies.

Recent evidence from antibody responses and T-cell proliferative responses suggests that there is an HLA-linked control of the differential immune responsiveness to microbial antigens (Kaslow and Shaw, 1981). This has been studied by measuring immune responsiveness to naturally acquired immunogens such as streptococcal cell-wall antigens (Greenberg, Gray and Yunis, 1975; Greenberg et al., 1980; Lehner et al., 1981) or to vaccination (Kato et al., 1978; Sasazuki et al., 1980; Nose et al., 1980). Many disease associations have been explained in this way. Ehrenkranz (1966) investigated the nasal rejection of experimentally inoculated $S$. aureus in non-carriers and found that the length of time taken to eliminate the bacteria was less on subsequent occasions than on the first and that this response was specific for the staphylococcal strain. Despite the fact that no difference in serum antibody levels to $S$. aureus has been detected between carriers and non-carriers (Daugharty, Martin and White, 1969), the ability to carry $S$. aureus may possibly be determined by an HLA-linked control of immunity to this organism. Perhaps the Gm genotype of the host may have a controlling influence, as has been recently suggested by Nakao et al. (1980) and Whittingham et al. (1980).

An alternative hypothesis is that carriers have receptors for this organism. Aly et al. (1977) showed that staphylococci adhered more to washed nasal epithelial cells of carriers than to cells of non-carriers. One suggestion for the association between HLA and infectious disease is that the HLA molecule acts as the receptor for organisms, but firm evidence for this is available in only a few instances (Helenius et al., 1978).

The mechanism of interaction between HLA gene products or HLA-linked gene products 
and microorganisms remains unclear, but the colonisation of nasal mucosa by $S$. aureus could serve as a model to investigate this further.

We thank Dr E. Albert, Tissue Typing Laboratory, University of Munich for providing the typing sera used in the Irish study, and the staff of the Tissue Typing and Immunology Laboratories at The London Hospital, Guy's Hospital, The Royal Marsden Hospital and The Imperial Cancer Research Fund for the results of tissue typing of the laboratory workers.

\section{REFERENCES}

Aly, R., Shinefield, H. I., Strauss, W. G. ANd MaibaCh, H. I. 1977. Bacterial adherence to nasal mucosal cells. Infection and Immunity, 17, 546-549.

Ayliffe, G. A. J., Brightwell, K. M., Collins, B. J., Lowbury, E. J. L., Goonatilake, P. C. L. AND ETHERIDGE, R. A. 1977. Surveys of hospital infection in the Birmingham Region. 1. Effect of age, sex, length of stay and antibiotic use on nasal carriage of tetracycline-resistant Staphylococcus aureus and on post-operative wound infection. Journal of Hygiene, 79, 299-314.

Daugharty, H. D., Martin, R. R. AND White, A. 1969. Reactions of sera and nasal secretions with staphylococcal antigens. Journal of Laboratory and Clinical Medicine, 73, 1011-1018.

EHRENKRANZ, N. J. 1966. Nasal rejection of experimentally inoculated Staphylococcus aureus: evidence for an immune reaction in man. Journal of Immunology, 96, 509-517.

Findlay, G. M. AND ABRahams, C. 1946. The incidence of staphylococci in the nose and on the skin of Africans and Europeans in West Africa. Journal of the Royal Army Medical Corps, 87, $272-274$.

Greenberg, L. J., ChopyK, R. L., Bradley, P. W. and Lalouel, J. M. 1980. Immunogenetics of response to a purified antigen from Group A streptococci. II. Linkage of response to HLA. Immunogenetics, 11, 161-167.

GreEnBerg, L. J., GrAy, E. D. AND YUNIS, E. J. 1975. Association of HL-A5 and immune responsiveness in vitro to streptococcal antigens. Journal of Experimental Medicine, 141, 935-943.

Helenius, A., AND 7 OTHERs. 1978. Human (HLA-A and HLA-B) and murine (H-2K and H-2D) histocompatibility antigens are cell surface receptors for Semliki Forest virus. Proceedings of the National Academy of Sciences, 75, 3846-3850.

Hoeksma, A. and WinkLer, K. C. 1963. The normal flora of the nose in twins. Acta Leidensia, 32, $123-133$.

KaSLOW, R. A. AND SHAW, S. 1981. The role of histocompatibility antigens (HLA) in infection. Epidemiologic Reviews, 3, edited by N. Nathanson and L. Gordis, Johns Hopkins University Press, Baltimore MD, pp. 90-114.

Kato, S., Kimura, M., Takakura, I., Sakakibara, T., Inouye, H. and Tsuji, K. 1978. Possible associations between HLA antigens and the immune responsiveness to attenuated rubella vaccine. Tissue Antigens, 11, 475-478.

Lehner, T., Lamb, J. R., Welsh, K. L. and Batchelor, R. J. 1981. Association between HLA-DR antigens and helper cell activity in the control of dental caries. Nature, 292, 770-772.

Millian, S. J., Baldwin, J. N., Rheins, M. S. AND Weiser, H. H. 1960. Studies on the incidence of coagulase positive staphylococci in a normal unconfined population. American Journal of Public Health, 50, 791-798.

NAKAO, Y., AND 9 OTHERS. 1980. IgG heavy chain allotypes $(\mathrm{Gm})$ in autoimmune diseases. Clinical and Experimental Immunology, 42, 20-26.

NoBlE, W. C. 1974. Carriage of $S$. aureus and beta haemolytic streptococci in relation to race. Acta Dermatovener (Stockholm), 54, 403-405.

Noble, W. C., Valkenburg, H. A. AND Wolters, C. H. L. 1967. Carriage of Staphylococcus aureus in random samples of a normal populations. Journal of Hygiene, Cambridge, 65, $567-573$.

Nose, Y., Komori, K., Inouye, H., Nomura, K., Yamamura, M. and Tsuji, K. 1980. 
Relationship between HLA-D and in vitro and in vivo responsiveness to Candida allergen. Clinical and Experimental Immunology, 40, 345-350.

Sasazuki, Y., Kaneoka, H., Nishimura, Y., Kaneoka, R., Hayama, M. and OhKuni, H. 1980. An HLA linked immune suppression gene in man. Journal of Experimental Medicine, 152, 297s-313s.

van Rood, J. J., van Leeuwen, A., Keuning, J. J., Blussé van Oud Alblas, A. 1975. The serological recognition of the human MLC determinants using a modified cytotoxicity technique. Tissue Antigens, 5, 73-79.

Whittingham, S., Mathews, J. D., Schanfield, M. S., Matthews, J.V., Tait, B. D., Morris, P. J. AND MACKAY, I. R. 1980. Interactive effect of $\mathrm{Gm}$ allotype and HLA B locus antigens on the human antibody response to a bacterial antigen. Clinical and Experimental Immunology, 40, 8-15.

WilliaMs, R. E. O. 1963. Healthy carriage of Staphylococcus aureus: its prevalence and importance. Bacteriological Reviews, 27, 56-71. 